\title{
Adduct under Field-A Qualitative Approach to Account for Solvent Effect on Hydrogen Bonding
}

\author{
Ilya G. Shenderovich ${ }^{1, *(1)}$ and Gleb S. Denisov ${ }^{2}$ \\ 1 Institute of Organic Chemistry, University of Regensburg, Universitaetstrasse 31, \\ 93053 Regensburg, Germany \\ 2 Department of Physics, Saint-Petersburg State University, 198504 Saint-Petersburg, Russia; \\ gldenisov@yandex.ru \\ * Correspondence: Ilya.Shenderovich@ur.de; Tel.:+49-941-9434027
}

Academic Editor: James Sherwood

Received: 1 January 2020; Accepted: 20 January 2020; Published: 21 January 2020

\begin{abstract}
The location of a mobile proton in acid-base complexes in aprotic solvents can be predicted using a simplified Adduct under Field (AuF) approach, where solute-solvent effects on the geometry of hydrogen bond are simulated using a fictitious external electric field. The parameters of the field have been estimated using experimental data on acid-base complexes in $\mathrm{CDF}_{3} / \mathrm{CDClF}_{2}$. With some limitations, they can be applied to the chemically similar $\mathrm{CHCl}_{3}$ and $\mathrm{CH}_{2} \mathrm{Cl}_{2}$. The obtained data indicate that the solute-solvent effects are critically important regardless of the type of complexes. The temperature dependences of the strength and fluctuation rate of the field explain the behavior of experimentally measured parameters.
\end{abstract}

Keywords: solvent effect; hydrogen bond; NMR; condensed matter; polarizable continuum model; reaction field; external electric field; proton transfer

\section{Introduction}

Proton transfer represents the simplest possible chemical reaction [1] and is ubiquitous in chemistry [2,3], material science [4-6], and biology [7,8]. In the latter case, the complexity of the process can increase to a hydrogen atom transfer $[9,10]$. In condensed matter, the mechanism and the pathway of proton transfer depend on the local environment. As a result, the study of proton transfer processes in a given system can be used as a tool to study the local environment. In most cases, it will require a theoretical simulation of the proton transfer under question. Such simulations are still very challenging as they depend on a compromise between the size of the modeled molecular system and the quality of accounting for intermolecular interactions. The size should be large enough to include all relevant interactions; the quality should be good enough to estimate their effect correctly. One may prefer to simulate a given molecular system in condensed matter using oversimplified approaches, looking only for a qualitative description of the system. Often, such approaches are fully justified. The available theories of nonadiabatic [11] and adiabatic [12] proton transfer reactions provide a useful background for understanding experimental results as on reversible proton transfer in the Zundel cation [13-15] as well as on fast proton dynamics in general [16-18]. The precision of such analysis can be improved further [19]. However, the most challenging part is to account for the effect of fluctuating solute-solvent interactions [20-22].

Often, one needs to restrict proton mobility in order to stabilize individual structures. This is especially important for high-resolution nuclear magnetic resonance spectroscopy (NMR) whose characteristic time is of the order of $10^{-3} \mathrm{~s}$. Basically, proton and molecular exchange can be suppressed by lowering the temperature. However, when studying intermolecular interactions in solution, one is strictly limited with the available temperature range. For aprotic polar solvents, the lowest 
possible temperature is about $100 \mathrm{~K}$ [23]. This temperature is not always low enough to affect proton dynamics [24,25]. Another problem is that the required temperature depends on intermolecular interactions in a complex way [26-28]. Even the structures of complexes with strong noncovalent interactions are affected by interactions with the environment [29-32]. In solution, this can be visualized by molecular dynamics simulations $[33,34]$. Thus, conventional gas-phase calculations can neither be used to predict at what temperature in a given molecular system proton exchange can be suppressed in a given solvent nor to simulate the mean structure of the system in solution.

Solvent effect can be divided into two parts: (i) fluctuating solute-solvent specific interactions and (ii) macroscopic electric field. The polarizable continuum model (PCM) includes only the latter effect [35]. As a result, this model is not sufficient to simulate the structure of noncovalently bound complexes in polar solvents [36]. The effects of specific solute-solvent interactions are to some extent implicitly included in the SMD (Solvation Model based on Density) model [37]. This model uses a number of solvent-specific parameters. In reality, the tabulated values of Abraham's hydrogen bond acidity and basicity, aromaticity, and electronegative halogenicity of solvents are not always the optimal choice for a given molecular system. The temperature dependence of these parameters is not known. Thus, given standard conditions, this model can be a good approximation and would fail otherwise. The problem can be overcome by using molecular dynamics approaches. However, they are computationally consuming and challenging when in non-aqueous solutions [38].

Alternatively, the effect of environment can be simulated using a fictitious external electric field [39-41]. The main advantage of this approach in relation to complexes with noncovalent interactions is that their experimental structures can be reproduced using only one parameter-the strength of the external electric field. The physical meaning of this field is illustrated in Figure 1. For the sake of simplicity, we consider a hydrogen-bonded (H-bond) complex in an aprotic polar solvent. The strongest intermolecular interaction in this complex is the acid-base H-bond. The geometry of this bond is affected by the macroscopic electric field generated by dipole moments of solvent molecules. This effect can be simulated by the PCM model. Besides that, there are weak yet multiple interactions with solvent molecules. They also cause changes in the electron density in the acid and base that affect the position of the mobile proton. The PCM model ignores this effect. The SMD model can include this effect through the empirical parameters. Using the external electric field model, we can estimate the relative amplitudes of both macroscopic and specific effects on the properties of the hydrogen bond under question when simulating a given experimental property of $\mathrm{H}$-bond with the external field alone and in combination with the PCM model. The efficiency of this Adduct under Field (AuF) approach was demonstrated using a complex of hydrogen fluoride with pyridine [42].

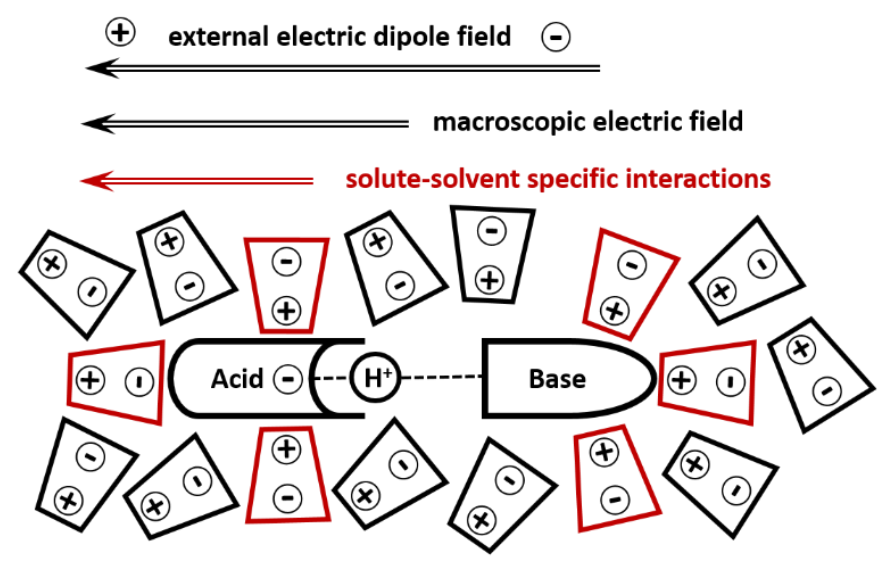

Figure 1. The direction of the external electric field that simulates the effect of solute-solvent interactions on the H-bond. 
In this work, we use the AuF model in order to simulate experimentally observed solvent-driven proton transfer in a number of H-bonded complexes. The aim of this study is to formulate a simplified computational approach capable of predicting the temperature at which proton exchange will be suppressed in any given solute-solvent system. The model molecular systems are shown in Figure 2. These complexes have been experimentally studied in the past in a liquid $\mathrm{CDF}_{3} / \mathrm{CDClF}_{2}$ mixture, exhibiting a dielectric constant between 20 at $170 \mathrm{~K}$ and 38 at $103 \mathrm{~K}$ [23]. The proton-bound homodimer of pyridine (1) does not have chemically active sites exposed to the solvent while the carboxylic moiety in 2-6 can specifically interact with solvent molecules [34].
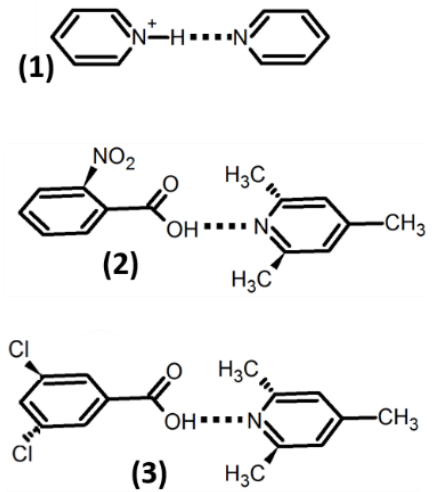
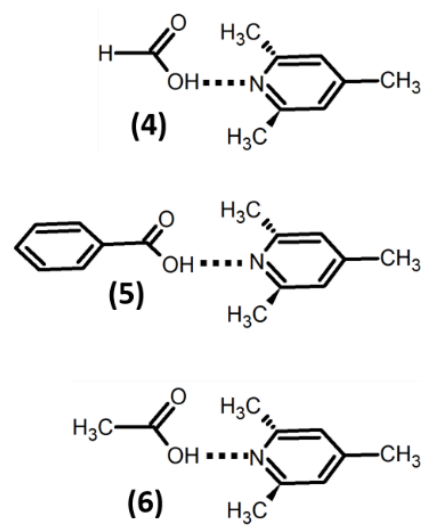

Figure 2. H-bonded complexes studied in this paper: proton-bound homodimer of pyridine (1) and complexes of 2,4,6-trimethylpyridine (collidine) with 2-nitrobenzoic acid (2), 3,5-dichlorobenzoic acid (3), formic acid (4), benzoic acid (5), and acetic acid (6).

Proton-bound homodimers can be of two types-symmetric, in which case the partners equally share the binding proton, and asymmetric, where the proton has a stronger bond to one of the partners at any given moment in time [43]. In the proton-bound homodimers of pyridine derivatives in $\mathrm{CDF}_{3} / \mathrm{CDClF}_{2}$ mixtures, the mobile proton jumps between the two bases faster than $10^{3} \mathrm{~s}^{-1}$ down to $120 \mathrm{~K}$ [44] and slower than $10^{11} \mathrm{~s}^{-1}$ up to $290 \mathrm{~K}$ [45].

In Table $1^{1} J\left({ }^{15} \mathrm{~N}^{1} \mathrm{H}\right)$ scalar coupling constants in $\mathbf{2}-6$ in $\mathrm{CDF}_{3} / \mathrm{CDClF}_{2}$ solution are collected [46]. These constants were measured at different temperatures-the reason being that above these temperatures the solvent-driven exchange between $\mathrm{O}-\mathrm{H} \cdots \mathrm{N}$ and $\mathrm{O}^{-} \cdots[\mathrm{H}-\mathrm{N}]^{+}$forms of the complexes was fast on the NMR time scale. Proton tautomerism in such complexes has previously been studied in detail [34]. For our purpose, it is important that the process strongly depends on the $\mathrm{p} K_{\mathrm{a}}$ of the involved acid. As a result, the solute-solvent interactions can be analyzed in a large temperature range. We know that in the $\mathrm{O}^{-} \ldots[\mathrm{H}-\mathrm{N}]^{+}$form ${ }^{1} J\left({ }^{15} \mathrm{~N}^{1} \mathrm{H}\right) \gtrsim 90 \mathrm{~Hz}$ [47]. Thus, for some of these complexes, the tautomerism can be slow on the NMR time scale of chemical shifts and fast on the NMR time scale of scalar couplings. However, such aspects are beyond the precision of our qualitative model.

Table 1. Experimental ${ }^{1} J\left({ }^{15} \mathrm{~N}^{1} \mathrm{H}\right)$ scalar couplings in $\mathbf{2}-\mathbf{6}$ in $\mathrm{CDF}_{3} / \mathrm{CDClF}_{2}$ solution [46].

\begin{tabular}{cccc}
\hline Complex & ${ }^{\mathbf{1}} \mathbf{J}^{\left({ }^{\mathbf{1 5}} \mathbf{N}^{\mathbf{1}} \mathbf{H}\right), \mathbf{H z}}$ & $\mathbf{T}, \mathbf{K}$ & $\mathbf{p K}_{\mathbf{a}}{ }^{\mathbf{1}}$ \\
\hline $\mathbf{2}$ & -87.0 & 200 & 2.16 \\
$\mathbf{3}$ & -81.1 & 130 & 3.46 \\
$\mathbf{4}$ & -79.1 & 120 & 3.75 \\
$\mathbf{5}$ & -76.9 & 120 & 4.19 \\
$\mathbf{6}$ & -65.4 & 110 & 4.75 \\
\hline
\end{tabular}

${ }^{1}$ The $\mathrm{p} K_{\mathrm{a}}$ 's of the involved acids. 


\section{Results}

\subsection{Proton-Bound Homodimer of Pyridine}

Figure 3a shows the potential energy curve of a non-adiabatic proton transfer in $\mathbf{1}$ under the PCM approximation at $\varepsilon=29.3$. The minimum energy structures of the pyridines of 1 are not equal. Therefore, when the mobile proton is transferred from one pyridine to the other while all other atoms are fixed, the second minimum has a larger energy. In reality, this fictitious profile is not present and only shown to illustrate further changes. The ground vibrational level of the proton is higher than the energy of the transition state. The frequency of the stretching vibration $\left(v_{N H N}\right)$ estimated under the harmonic approximation is $2486 \mathrm{~cm}^{-1}$. While the potential is anharmonic, this value is a rough estimate and is given for illustrative purposes only [48]. The accuracy of the calculations can only be increased at the cost of making them very time-consuming [49,50]. The value of $\varepsilon$ can also be challenged; in $\mathrm{CDF}_{3} / \mathrm{CDClF}_{2}$ solution at about $130 \mathrm{~K} \varepsilon \approx 30$ [23]. However, the non-adiabatic proton transfer depends on an optical dielectric constant of about 2 [16]. Under the gas phase harmonic approximation, $v_{N H N}=2142 \mathrm{~cm}^{-1}$. Thus, a qualitatively similar potential surface will be observed for any value of $\varepsilon$. We are interested in the situation when this transfer is suppressed. What is important is that solvent polarization alone cannot cause this effect.

$\mathrm{CDF}_{3} / \mathrm{CDClF}_{2}$ solution cannot be simulated using the SMD approximation because its parameters are not known. Instead, chemically similar $\mathrm{CH}_{2} \mathrm{Cl}_{2}$ can be used. Although $v_{N H N}$ increases under this approximation to $2517 \mathrm{~cm}^{-1}$, it is still higher than the energy of the transition state, Figure $3 \mathrm{~b}-$ meaning that this model cannot reproduce the experimentally observed single-well location of the mobile proton in 1.

The single-well location becomes possible in the presence of an external electric field. Under the PCM approximation ( $\varepsilon=29.3$ ) and the field of 0.001 a.u., the energy of the ground vibrational level of the mobile proton is very close to the energy of the transition state, Figure 3c. At 0.002 a.u., the former is lower than the latter, Figure $3 \mathrm{~d}$. This increase of the field is accompanied by an increase of $v_{N H N}$ from $2593 \mathrm{~cm}^{-1}$ to $2684 \mathrm{~cm}^{-1}$, Figure 3c,d. Thus, the experimentally observed proton jumps in 1 can be simulated under the PCM approximation and $\varepsilon \approx 30$ when the strength of the external field is above 0.001-0.002 a.u. There is no hard criteria for choosing the most appropriate value of the field. We can only state that the lower limit of its strength is 0.001 a.u. Within the gas phase approximation, this limits increases to at least 0.003 a.u., Figure 3e,f. 

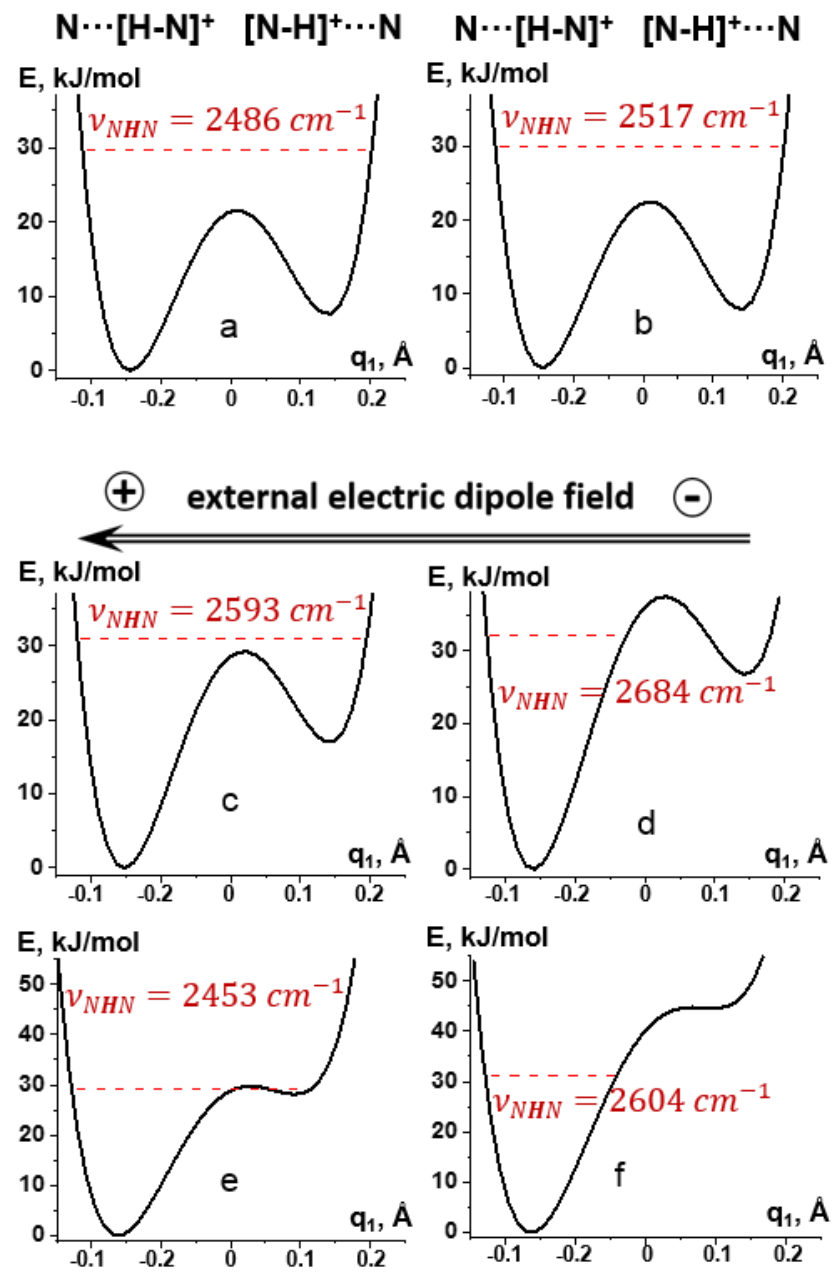

Figure 3. Potential energy curve of a proton transfer within 1 at different approximations: (a) PCM ( $\varepsilon=29.3)$, (b) SMD $\left(\mathrm{CH}_{2} \mathrm{Cl}_{2}, \varepsilon=8.9\right)$, (c) PCM ( $\left.\varepsilon=29.3\right)$ and the external electric field of 0.001 a.u., (d) PCM ( $\varepsilon=29.3)$ and the external electric field of 0.002 a.u., (e) the external electric field of 0.003 a.u., and (f) the external electric field of 0.005 a.u. Dashed lines indicate the energy of the ground state. $v_{N H N}$ are the frequencies of the mobile proton stretching vibration. $\mathrm{q}_{1}$ corresponds to the distance of the mobile proton with respect to the H-bond center [51].

\subsection{Complexes of Collidine with Acids}

In Table 2, geometric parameters of H-bond in 4 under different approximations are reported. Although these parameters depend on the level of approximation, the mobile proton is located at the acid in all cases. Only at $\varepsilon>29$ do there appear higher energy local minima on the potential energy curve of proton transfer that correspond to the proton location at collidine. Taking into account a qualitative character of our analysis, we studied the effect of the external electric field on the location of the mobile proton in 2-6 at a computationally efficient $w \mathrm{~B} 97 \mathrm{XD} / \mathrm{def} 2 \mathrm{svp}$ approximation. We also restricted our analysis to the comparison of the difference between the energies of the two minima (proton at acid and proton at base) on the potential energy curve of proton transfer. The values of $\varepsilon$ under the PCM approximation were taken equal to 12.5 for $\mathbf{2}$ and 29.3 for 3-6. These values are close to the dielectric constant of $\mathrm{CDF}_{3} / \mathrm{CDClF}_{2}$ solution at $200 \mathrm{~K}$ and $130 \mathrm{~K}$, respectively [23]. There is no need to select $\varepsilon$ with a higher precision because Table 2 clearly demonstrates that, at $\varepsilon>10$, its effect on H-bond geometry remains rather constant. 
Table 2. H-bond geometry of 4 under different DFT (Density Functional Theory) approximations.

\begin{tabular}{|c|c|c|c|c|}
\hline DFT Functional & Basis Set & $\mathrm{PCM}, \varepsilon$ & $\mathbf{N} \cdots \mathbf{H}, \AA$ & $\mathbf{N} \ldots \mathrm{O}, \AA$ \\
\hline wB97XD & def $2 s v p$ & - & 1.689 & 2.696 \\
\hline wB97XD & def2svpp & - & 1.655 & 2.674 \\
\hline wB97XD & def2tzvp & - & 1.701 & 2.709 \\
\hline wB97XD & def2tzvpp & - & 1.707 & 2.712 \\
\hline B2PLYPD3, gd3 & def2svp & - & 1.692 & 2.697 \\
\hline B2PLYPD3, gd3 & def2svpp & - & 1.677 & 2.694 \\
\hline B2PLYPD3, gd3 & def2tzvp & - & 1.687 & 2.700 \\
\hline B2PLYPD3, gd3 & def2tzvpp & - & 1.694 & 2.703 \\
\hline wB97XD & def2svp & 12.5 & 1.625 & 2.650 \\
\hline wB97XD & $\operatorname{def} 2 \mathrm{svp}$ & 29.3 & 1.620 & 2.647 \\
\hline wB97XD & def2svp & 46.8 & 1.619 & 2.646 \\
\hline wB97XD & def2svp & 108.9 & 1.617 & 2.645 \\
\hline
\end{tabular}

Figure 4 demonstrates the effect of the external electric field on the energy of the molecular $(\mathrm{O}-\mathrm{H} \cdots \mathrm{N})$ and ionic $\left(\mathrm{O}^{-} \cdots[\mathrm{H}-\mathrm{N}]^{+}\right)$forms of $\mathrm{H}-$ bonds in 2 (Figure $\left.4 \mathrm{a}, \mathrm{b}\right), 3$ (Figure $4 \mathrm{c}, \mathrm{d}$ ), 4 (Figure 4e,f), 5 (Figure 4g,h), and 6 (Figure 4i,j) under the PCM and gas-phase approximations. For all complexes in both approximations, an increase of the field causes an energy decrease of both forms, although the favor is towards the ionic one. Upon this increase, the profile of a potential energy curve changes from a single-well (molecular) to a double-well to a single-well (ionic) one. The double-well potential interval is shown in Figure 4. For each complex, there is a unique value of the field strength for which the energy minima of the two forms are equal. $\Delta E$ corresponds to the energy of the complex with respect to the value at this field.

Strictly speaking, in order to find which value of the external field is the best approximation of experimental conditions, one needs (i) to estimate the molar fractions of the two forms from NMR spectra and (ii) to then find at what field the same ratio is be obtained in calculations. The former can be done using either the value of ${ }^{1} J\left({ }^{15} \mathrm{~N}^{1} \mathrm{H}\right)$ in Table 1 or the ${ }^{1} \mathrm{H}-\mathrm{NMR}$ chemical shift of the mobile proton [52]; the latter-by calculating the effect of the field on the free energy. However, both of these estimates are rough and are redundant in the case of the present qualitative analysis. Instead, the lower limit of the external electric field can be associated to the value at which the energy minima of the two forms are equal, Table 3.

Table 3. The external electric field at which the energy minima of the molecular $(\mathrm{O}-\mathrm{H} \cdots \mathrm{N})$ and ionic $\left(\mathrm{O}^{-} \ldots[\mathrm{H}-\mathrm{N}]^{+}\right)$forms of $\mathrm{H}$-bonds in $\mathbf{2}-\mathbf{6}$ are equal.

\begin{tabular}{cccccc}
\hline Method & $\mathbf{2}$ & $\mathbf{3}$ & $\mathbf{4}$ & $\mathbf{5}$ & $\mathbf{6}$ \\
\hline Field, a.u. \& & 0.0004 & 0.0005 & 0.0015 & 0.0014 & 0.0027 \\
PCM $\varepsilon=$ & 12.5 & 29.3 & 29.3 & 29.3 & 29.3 \\
Field, a.u. (gas-phase) & 0.0044 & 0.0046 & 0.0075 & 0.0061 & 0.0082 \\
\hline
\end{tabular}


$\oplus$ external electric dipole field
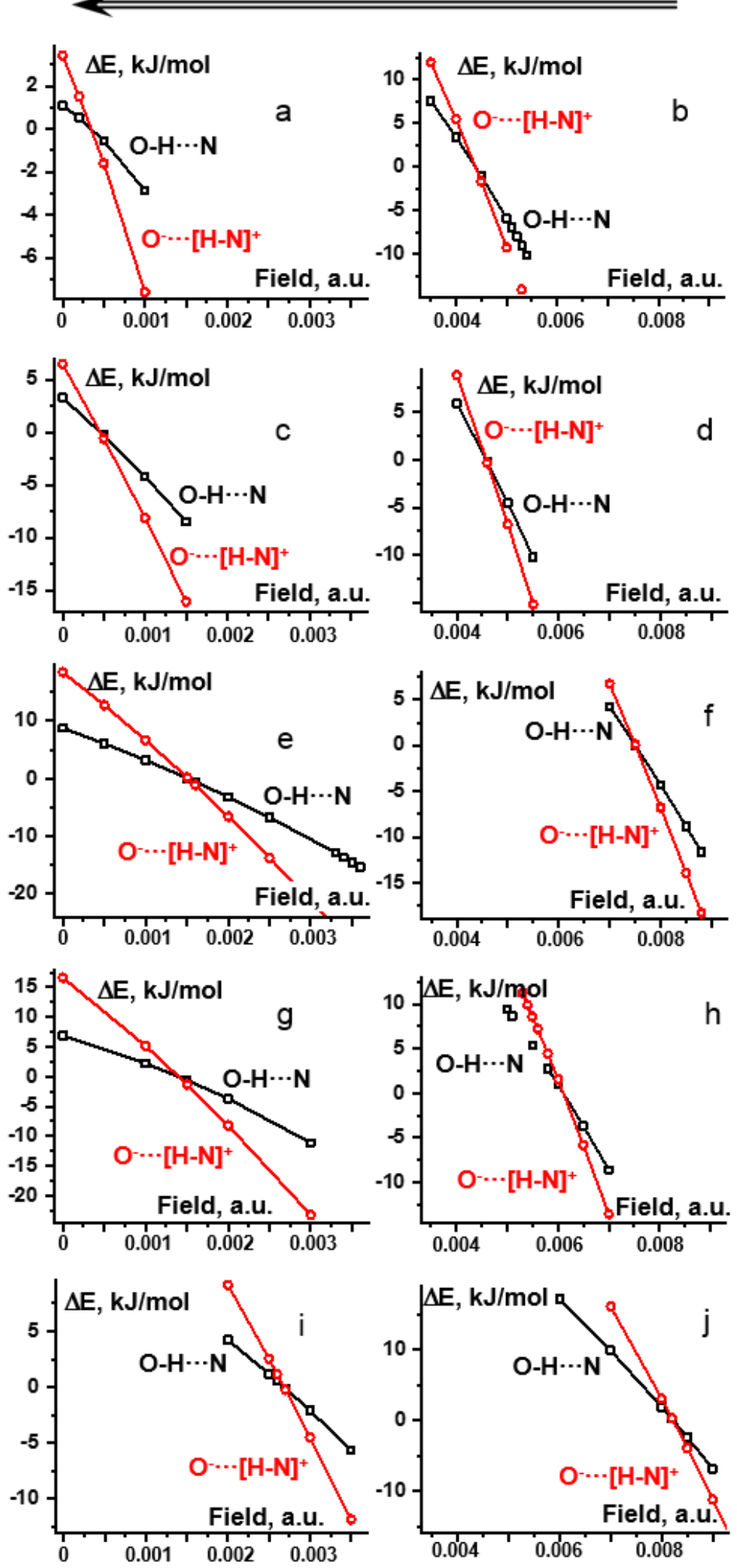

Figure 4. The effect of the external electric field on the energy of $\mathrm{O}-\mathrm{H} \cdots \mathrm{N}$ (black $\square$ ) and $\mathrm{O}^{-} \cdots[\mathrm{H}-\mathrm{N}]^{+}$ (red $\bigcirc$ ) forms of H-bonds in 2-6. For each complex, there is a unique value of the field strength for which the energy minima of the two forms are equal. $\Delta E$ corresponds to the energy with respect to the value at this field. 2: (a) PCM ( $\varepsilon=12.5)$, (b) gas-phase; 3: (c) PCM ( $\varepsilon=29.3)$, (d) gas-phase; 4: (e) PCM $(\varepsilon=29.3)$, (f) gas-phase; 5: (g) PCM ( $\varepsilon=29.3)$, (h) gas-phase; 6: (i) PCM ( $\varepsilon=29.3)$, (j) gas-phase. 


\subsection{The Gas-Phase Proton Affinities}

For the further discussion of the obtained results, we will use the values of the gas-phase proton affinities (PA). These values are listed in Table 4 for a number of selected proton acceptors.

Table 4. Gas-phase proton affinities of selected proton acceptors.

\begin{tabular}{cccccc}
\hline Acceptor & $\mathbf{P A}, \mathbf{k J} / \mathbf{m o l}$ & Acceptor & $\mathbf{P A}, \mathbf{k J} / \mathbf{m o l}$ & Acceptor & $\mathbf{P A}, \mathbf{k J} / \mathbf{m o l}$ \\
\hline pyridine & 936 & 2-nitrobenzoate & 1382 & Formate & 1431 \\
collidine & 988 & 3,5-dichlorobenzoate & 1379 & Acetate & 1447 \\
benzoate & 1421 & 4-nitrophenolate & 1354 & fluoride & 1547 \\
& & $\mathrm{~F}^{-}$...HCF & & \\
\end{tabular}

\section{Discussion}

Figure 5 shows lower limits of the external electric fields simulated the effect of $\mathrm{CDF}_{3} / \mathrm{CDClF}_{2}$ on 1-6 under the PCM (5a) and gas-phase (5b) approximations as a function of the $\mathrm{p} K_{\mathrm{a}}$ of the proton-donor. The $\mathrm{p} K_{\mathrm{a}}$ of pyridine is 5.32 [46]; other values are listed in Table 1; Table 3. For 2-6, the strength of the field required to transfer the proton to the base correlates with the strength of the acids in both approaches. 1 deviates strongly from these correlations as it should. The energy minima of two tautomeric forms of $\mathbf{1}$ are equal at zero field. The values shown for $\mathbf{1}$ (Figure 5) correspond to the case when this double-well potential energy curve becomes a single-well one (Figure 3). However, in contrast to 2-6, proton tautomerism in $\mathbf{1}$ remains fast on the NMR time scale. Thus, the physical meanings of the values reported here for 2-6 and $\mathbf{1}$ are different. What is important is that (i) the order of magnitude of the electric field simulated the effect of $\mathrm{CDF}_{3} / \mathrm{CDClF}_{2}$ on $\mathbf{1}, \mathbf{2}-\mathbf{6}$, and pyridine $\cdots \mathrm{HF} \cdots\left(\mathrm{HCF}_{3}\right)_{\mathrm{n}}$ [42] is the same and (ii) its effect on $\mathrm{H}$-bond geometry correlates with the proton donating power of involved acids. The former means that the AuF approach is appropriate for a qualitative description of solute-solvent interactions. The latter suggests that it should be possible to predict the effect of a given solvent on the geometry of a given H-bonded complex. What is the most reliable representation of the correlation between the expected strength of the external electric field and the chemical properties of involved acids and bases?

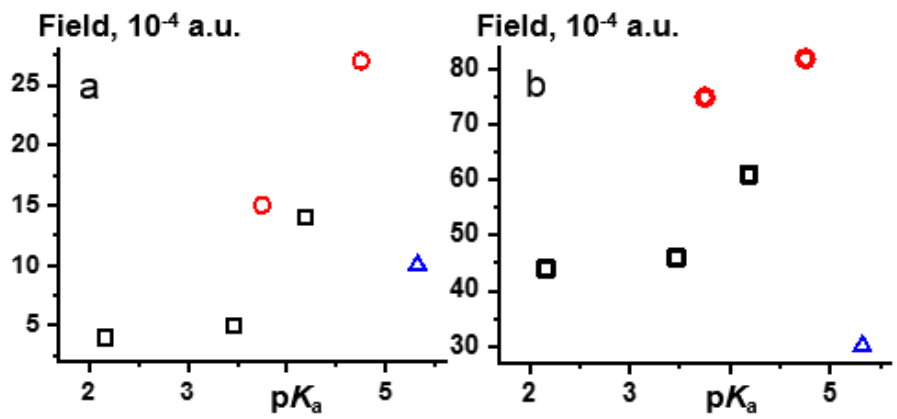

Figure 5. The lower limit of the external electric field simulated the effect of $\mathrm{CDF}_{3} / \mathrm{CDClF}_{2}$ on 2, 3, 5 (black $\square$ ), 4, 6 (red $\bigcirc$ ), and 1 (blue $\Delta$ ) under the PCM (a) and gas-phase (b) approximations as a function of the $\mathrm{p} K_{\mathrm{a}}$ of the proton-donor.

The use of $\mathrm{pK} \mathrm{a}_{\mathrm{a}}$ as a measure of acid's proton-donating power in non-aqueous solutions introduces an error into the correlation. The reason is that the $\mathrm{p} K_{\mathrm{a}}$ depends on solvation in water that is very specific solvent [53-55]. The pKa's of ionizable groups in a non-aqueous environment can be estimated theoretically [56]. However, such calculations are quite demanding. Alternatively, they can be empirically corrected to a solvent under question [57]. The easiest way to estimate the proton-donating and proton-accepting powers is to calculate the gas-phase proton affinity (PA), Table $4[58,59]$. These values are very close to available experimental data for pyridine $(930$ 
$\mathrm{kJ} / \mathrm{mol})[60,61]$, collidine (980 kJ/mol) [61], benzoate (1422 kJ/mol) and 2-nitrobenzoate (1383 kJ/mol) [62], formate $(1445 \mathrm{~kJ} / \mathrm{mol})$ and acetate $(1456 \mathrm{~kJ} / \mathrm{mol})$ [63], and fluoride $(1550 \mathrm{~kJ} / \mathrm{mol})[64]$.

Figure 6 demonstrates the lower limits of the external electric field simulated the effect of $\mathrm{CDF}_{3} / \mathrm{CDClF}_{2}$ on 2-6 under the PCM (Figure 6a) and gas-phase (Figure 6b) approximations as a function of the PA of the involved conjugate bases. We are aware that the use of the PCM approximation perturbs such correlations due to its dependence on the size of a molecular complex under study [58]. Therefore, we intend to use the gas-phase approximation. The analytical expression for the correlation shown in Figure $6 \mathrm{~b}$ is:

$$
F^{\text {gas }}[\text { in a.u. }]=\{(0.55 \pm 0.07) \cdot P A[\text { in } \mathrm{kJ} / \mathrm{mol}]-(700 \pm 100)\} \cdot 10^{-4} .
$$
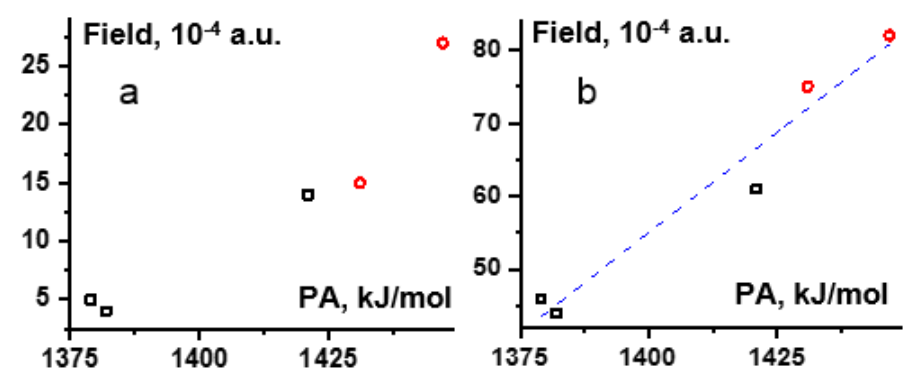

Figure 6. The lower limit of the external electric field simulated the effect of $\mathrm{CDF}_{3} / \mathrm{CDClF}_{2}$ on 2, 3, 5 (black $\square$ ) and 4, 6 (red $\bigcirc$ ) under the PCM (a) and gas-phase (b) approximations as a function of the PA of the involved acids.

This correlation can be generalized by replacing the PA of the conjugate bases with a difference between the PA's of a proton donor (conjugate base) and an acceptor: $\triangle P A=P A^{\text {donor }}-P A^{\text {acceptor }}$. The analytical expression for this final correlation as shown in Figure 7 is:

$$
F^{\text {gas }}[\text { in a.u. }]=1.3 \cdot 10^{-4} \cdot\{\exp (0.009 \cdot \Delta P A[\text { in } \mathrm{kJ} / \mathrm{mol}])-1\} .
$$

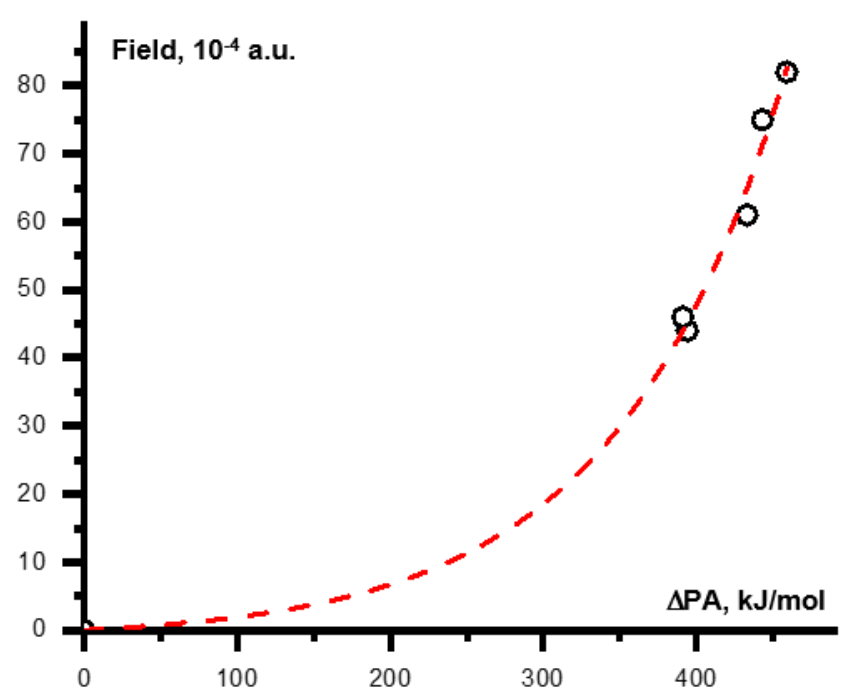

Figure 7. A functional dependence between the lower limit of the external electric field at which the energy minima of the Acid-H...Base and Acid $^{-} \ldots[\mathrm{H}-\mathrm{Base}]^{+}$forms of an H-bonded complex in $\mathrm{CDF}_{3} / \mathrm{CDClF}_{2}$ are equal and the difference between the PAs of a proton donor and an acceptor, $\triangle P A$. 
Here, $F^{g a s}$ tends to zero as $\triangle P A$ tends to zero that is physically correct. Results obtained for $\mathbf{1}$, 2, and 6 provide limiting values for the strengths of the external electric field simulated the effect of $\mathrm{CDF}_{3} / \mathrm{CDClF}_{2}$ on $\mathrm{H}$-bond geometry at $300 \mathrm{~K}, 200 \mathrm{~K}$, and $100 \mathrm{~K}$, respectively. When the gas-phase approximation is used for the field-strength calculations, these values are about 0.003 a.u., 0.004 a.u., and 0.082 a.u., respectively. Only a part of this field can be associated to solvent polarization and accounted for in the frameworks of the PCM approach. The effect of this contribution on H-bond geometry is roughly constant and temperature independent. Another part of the field simulates the effect of solute-solvent interactions. Their impact is fluctuating and depends on temperature. Let us estimate the magnitudes of these two contributions.

For 1, the lower limit of the external electric field estimated under the PCM approximations is about 0.001 a.u. This value can be associated to the effect of solute-solvent interactions. Notice that both pyridines of 1 are affected by these interactions - meaning that 0.001 a.u. reflects the difference between the effects of solvation on the protonated pyridine and the $\mathrm{H}$-bonded one. This value fluctuates faster than $10^{3} \mathrm{~s}^{-1}$ down to $120 \mathrm{~K}$ and slower than $10^{11} \mathrm{~s}^{-1}$ up to $290 \mathrm{~K}[44,45]$. As a result, proton exchange within $\mathbf{1}$ is fast on the NMR and slow on the IR time scales in this temperature range.

Proton tautomerism acceptor $\cdots H$-donor $\rightleftharpoons$ acceptor $-H]^{+} \ldots$ (donor) ${ }^{-}$in $\mathrm{CDF}_{3} / \mathrm{CDClF}_{2}$ is strongly shifted

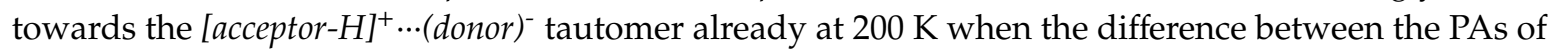
the proton donor and the acceptor is smaller than $400 \mathrm{~kJ} / \mathrm{mol}, 2$. The larger the difference, the lower the temperature should be. In $\mathrm{CDF}_{3} / \mathrm{CDClF}_{2}$, at the lowest experimentally achievable temperature of $100 \mathrm{~K}$, this tautomer dominates completely only when $\triangle P A$ is smaller than $500 \mathrm{~kJ} / \mathrm{mol}, 6$. The lower limits of the external electric field estimated under the PCM approximations required to stabilize the

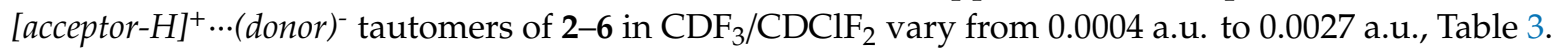
However, in contrast to $\mathbf{1}$, these values fluctuate slow on the NMR time scale. Tentatively, this field can mostly be associated to solvation of the carbonyl group. The lower the temperature, the more stable the interaction with solvent molecules. For a rough estimate, it can be assumed that the value of this slow fluctuating field increases from 0.0005 a.u. to 0.0030 a.u. in the temperature range from $200 \mathrm{~K}$ to $100 \mathrm{~K}$.

For the chemically similar $\mathrm{CH}_{2} \mathrm{Cl}_{2}$, the lowest experimentally achievable temperature is about $170 \mathrm{~K}$ [27]. Thus, when $\triangle P A$ is smaller than $400 \mathrm{~kJ} / \mathrm{mol}$, the [acceptor $-H]^{+} \ldots(\text { donor })^{-}$tautomer should dominate. This estimate can be checked using a complex of 4-nitrophenol with acetate in $\mathrm{CD}_{2} \mathrm{Cl}_{2}$ [65]. In this complex, $\triangle P A=P A^{\text {acetate }}-P A^{\text {phenolate }}=93 \mathrm{~kJ} / \mathrm{mol}$, Table 4 . At $173 \mathrm{~K}$, the phenol $\cdots(\text { acetate })^{-}$form of the complex dominated. Ab initio molecular dynamics demonstrated that this form was stabilized by interactions of the carbonyl group with solvent molecules. This interaction is implicitly included in our correlation. Formally speaking, these results support our estimate. However, molecular dynamics showed that the location of a tetraalkylammonium anion was also critically important in this case. This interaction is not covered by our correlation. This effect is absent for charged H-bonded complexes only for very bulky anions [25]. Notice that solvation of the phenolate oxygen will reduce the effect of the carbonyl solvation.

The importance of specific interactions is extreme in the case of a complex of pyridine with hydrogen fluoride. This complex was studied by NMR [23,66] and model calculations [43,67]. The strength of the external electric field, at which the experimental geometry of the $\mathrm{N} \cdots \mathrm{H}$ and $\mathrm{H}-\mathrm{F}$ bonds of pyridine $\cdot \mathrm{HF}$ in $\mathrm{CDF}_{3} / \mathrm{CDClF}_{2}$ is reproduced, depends on the number of the solvent molecules coordinated to the fluorine in model adducts pyridine $\cdots \mathrm{HF} \cdots\left(\mathrm{HCF}_{3}\right)_{\mathrm{n}}$. It is about 0.017 a.u. for pyridine $\cdots \mathrm{HF}, 0.010$ a.u. for pyridine $\cdots \mathrm{HF} \cdots \mathrm{HCF}_{3}$, and 0.006 a.u. for pyridine $\cdots \mathrm{HF} \cdots\left(\mathrm{HCF}_{3}\right)_{2}$. For the former adduct, $\triangle P A=611 \mathrm{~kJ} / \mathrm{mol}$, Table 4 . For pyridine $\cdots \mathrm{HF} \cdot \mathrm{HCF}_{3}$, the structure of the proton donor is $\mathrm{HF} \cdot \mathrm{HCF}_{3}$ and $\triangle P A=493 \mathrm{~kJ} / \mathrm{mol}$. It is not clear how to estimate the PA of $\mathrm{F}^{-} \cdots\left(\mathrm{HCF}_{3}\right)_{2}$ because the structure of such composite donor critically depends on its protonation state. In any case, it should be smaller than $500 \mathrm{~kJ} / \mathrm{mol}$ that explains a near central location of the mobile proton between the nitrogen and fluorine atoms as observed in experiments. Thus, also for this complex, our qualitative analysis agrees with a high-level molecular dynamics [33]. 


\section{Materials and Methods}

Gaussian 09.D.01 program package was used [68]. If not stated otherwise, geometry optimizations were done at the $w \mathrm{~B} 97 \mathrm{XD} / \mathrm{def} 2 \mathrm{tzvpp}$ and $w \mathrm{~B} 97 \mathrm{XD} / \mathrm{def} 2 \mathrm{svp}$ approximations for $\mathbf{1}$ and 2-6, respectively $[69,70]$. The identity of minima was confirmed by the absence of imaginary vibrational frequencies. The default SCRF=PCM method has been used to construct the solute cavity. The parameters for SMD calculations were adapted from the Minnesota Solvent Descriptor Database: eps $=8.93$, epsinf $=1.4242, \mathrm{H}$-bond acidity $=0.1, \mathrm{H}$-bond basicity $=0.05$, surface tension at interface $=$ 39.15 , carbon aromaticity $=0.0$, electronegative halogenicity $=0.667$ [71]. Although the SMD model was parametrized for the Minnesota functionals family, for the qualitative analysis presented in this work, we decided to use the same functional for all types of calculations.

The external electric field was added to calculations using a keyword Field. The $C_{2}$ symmetry axis of pyridine or collidine was fixed along the direction of the field using a keyword Z-Matrix. The electric dipole field in Gaussian is directed from the negative to the positive potential that is opposite to the conventional direction of electric field.

The gas-phase proton affinities (PA) were calculated as follows:

$$
P A=\Delta H^{298}(B)+5 R T / 2-\Delta H^{298}(B H) .
$$

Here, $\Delta H^{298}(B)$ and $\Delta H^{298}(B H)$ stand for the sums of the electronic and thermal enthalpies of a base and its conjugate acid or the conjugate base of an acid and the acid at $298 \mathrm{~K}$. The enthalpies were estimated at the B3LYP/6-311++g(3df,2p) level. This level provides a reasonable description of the structure and harmonic frequencies of the neutral and charged H-bonded systems in the gas phase [72]. It is also sufficient to obtain correct values of enthalpies [73].

\section{Conclusions}

The gas-phase proton affinity (PA) of conjugate bases is larger than that of most neutral bases. Proton transfer in condensed matter requires either an H-bond network [74] or solvation [54,75]. In specific cases, small alterations can cause pronounced changes [76]. Therefore, neither gas-phase nor PCM calculations can reproduce the geometry of an acid-base complex in condensed matter, if its environment is ignored. In contrast, useful qualitative data can be obtained using the Adduct under Field (AuF) approach. The weak yet multiple interactions between the acid-base complex and solvent molecules influence the electron density in the acid and base that affects the position of the mobile proton. These changes can be simulated using a fictitious external electric field. The macroscopic electric field can be either accounted for by the PCM approach or included in the strength of the field. The strength of the solute-solvent interactions fluctuates and its effective magnitude depends on temperature. In this paper, we report estimates of the strength of the fictitious field that simulates solvation effect of $\mathrm{CDF}_{3} / \mathrm{CDClF}_{2}$ on homo- and heterogeneous acid-base complexes in the temperature range from $300 \mathrm{~K}$ to $100 \mathrm{~K}$. With some limitations, the obtained results can be extended onto the chemically similar $\mathrm{CHCl}_{3}$ and $\mathrm{CH}_{2} \mathrm{Cl}_{2}$. The computational simplicity of the AuF approach could lend itself to wide application including large molecular systems [77-80].

In the presence of the external electric field, the potential energy curve of a proton transfer within the proton-bound homodimers of pyridines changes from a symmetric double-well potential to an asymmetric single-well one. In the temperature range $120-290 \mathrm{~K}$, the fluctuation rate of this field is between $10^{3}$ and $10^{11} \mathrm{~s}^{-1}$ that defines the rate of proton exchange within the homodimers. The lower limits of this field are reported above. For $[\mathrm{FHF}]^{-}[81,82]$ or $\left[\mathrm{H}_{2 n+1} \mathrm{O}_{n}\right]^{+}$[83] proton-bound homodimers, the same strength of the field can be an acceptable approximation only when several solvent molecules are explicitly included into calculations.

Below $200 \mathrm{~K}$, solvent effects on heterogeneous acid-base complexes can be simulated using a quasi-constant fictitious field. For complexes of pyridine with carboxylic acids, the strength of this field and its temperature dependence are reported above. For complexes of pyridine with 
alcohols and phenols, the strength will be smaller because interaction of the carbonyl oxygen with solvent molecules increases the proton-donating power of the hydroxylic group of carboxylic acids. When a proton-donating or proton-accepting center is open for a strong interaction with solvent molecules, these molecules should be included into the model adduct. See, for example, pyridine $\cdots \mathrm{HF} \cdots \mathrm{HCF}_{3}$ and pyridine $\cdots \mathrm{HF} \cdots\left(\mathrm{HCF}_{3}\right)_{2}$ adducts.

The most important conclusion of this study is that solute-solvent interactions remarkably affect the geometry of acid-base complexes in aprotic solvents even if the active sites of these complexes are not accessible for solvent molecules. As a result, these complexes exhibit proton tautomerism acceptor $\cdots H$-donor $\rightleftharpoons$ [acceptor $-H]^{+} \ldots(\text { donor })^{-}$in a large temperature range. The rate of this process is often slow on the time scales of electronic excitations and molecular vibrations while fast on the time scale of NMR. Therefore, both tautomers can be observed in the former cases while exchange averaged parameters will be obtained in the latter. Only in the presence of moderately strong solvation effects, for example, when solvent molecules interact with the proton-donating group, can the lifetime of the [acceptor-H] $]^{+} . .(\text {donor })^{-}$tautomer become long on the NMR time scale in the temperature range from $200 \mathrm{~K}$ to $100 \mathrm{~K}$.

Author Contributions: Conceptualization, I.G.S.; methodology, I.G.S. and G.S.D.; data curation, G.S.D.; writing — original draft preparation, I.G.S.; writing — review and editing, G.S.D.; visualization, I.G.S.; supervision, I.G.S. All authors have read and agreed to the published version of the manuscript.

Funding: This research was funded by the Russian Foundation of Basic Research (Project 20-03-00231). APC was sponsored by MDPI.

Acknowledgments: The authors gratefully acknowledge the Gauss Centre for Supercomputing e.V. (www.gausscentre.eu) for funding this project by providing computing time on the GCS Supercomputer SuperMUC at Leibniz Supercomputing Centre (LRZ, www.lrz.de).

Conflicts of Interest: The authors declare no conflict of interest.

\section{References}

1. Hynes, J.T.; Klinman, J.P.; Limbach, H.H.; Schowen, R.L. (Eds.) Hydrogen-Transfer Reactions; WILEY-VCH: Weinheim, Germany, 2007. [CrossRef]

2. Berendsen, H.J.C.; Mavri, J. Quantum Simulation of Reaction Dynamics by Density-Matrix Evolution. J. Phys. Chem. 1993, 97, 13464-13468. [CrossRef]

3. Bekcioglu, G.; Allolio, C.; Sebastiani, D. Water Wires in Aqueous Solutions from First-Principles Calculations. J. Phys. Chem. B 2015, 119, 4053-4060. [CrossRef] [PubMed]

4. Ciacka, P.; Fita, P.; Listkowski, A.; Radzewicz, C.; Waluk, J. Evidence for Dominant Role of Tunneling in Condensed Phases and at High Temperatures: Double Hydrogen Transfer in Porphycenes. J. Phys. Chem. Lett. 2016, 7, 283-288. [CrossRef] [PubMed]

5. Kabbe, G.; Dressler, C.; Sebastiani, D. Toward Realistic Transfer Rates within the Coupled Molecular Dynamics/Lattice Monte Carlo Approach. J. Phys. Chem. C 2016, 120, 19905-19912. [CrossRef]

6. Piwonski, H.; Sokolowski, A.; Kijak, M.; Nonell, S.; Waluk, J. Arresting Tautomerization in a Single Molecule by the Surrounding Polymer: 2,7,12,17-Tetraphenyl Porphycene. J. Phys. Chem. Lett. 2013, 4, 3967-3971. [CrossRef]

7. Karerlin, S.C.L.; Mavri, J.; Warshel, A. Examining the Case for the Effect of Barrier Compression on Tunneling, Vibrationally Enhanced Catalysis, Catalytic Entropy and Related Issues. FEBS Lett. 2010, 584, 2759-2766. [CrossRef]

8. Chan-Huot, M.; Dos, A.; Zander, R.; Sharif, S.; Tolstoy, P.M.; Compton, S.; Fogle, E.; Toney, M.D.; Shenderovich, I.; Denisov, G.S.; et al. NMR Studies of Protonation and Hydrogen Bond States of Internal Aldimines of Pyridoxal 5'-Phosphate Acid-Base in Alanine Racemase, Aspartate Aminotransferase, and PolyLlysine. J. Am. Chem. Soc. 2013, 135, 18160-18175. [CrossRef]

9. Prah, A.; Franciskovic, E.; Mavri, J.; Stare, J. Electrostatics as the Driving Force Behind the Catalytic Function of the Monoamine Oxidase A Enzyme Confirmed by Quantum Computations. ACS Catal. 2019, 9, 1231-1240. [CrossRef] 
10. Pregeljc, D.; Jug, U.; Mavri, J.; Stare, J. Why Does the Y326I Mutant of Monoamine Oxidase B Decompose an Endogenous Amphetamine at a Slower Rate Than the Wild Type Enzyme? Reaction Step Elucidated by Multiscale Molecular Simulations. Phys. Chem. Chem. Phys. 2018, 20, 4181-4188. [CrossRef]

11. Borgis, D.C.; Lee, S.; Hynes, J.T. A dynamical theory of nonadiabatic proton and hydrogen atom transfer reaction rates in solution. Chem. Phys. Lett. 1989, 162, 19-26. [CrossRef]

12. Kiefer, P.M.; Hynes, J.T. Nonlinear Free Energy Relations for Adiabatic Proton Transfer Reactions in a Polar Environment. II. Inclusion of the Hydrogen Bond Vibration. J. Phys. Chem. A 2002, 106, 1850-1861. [CrossRef]

13. Dahms, F.; Fingerhut, B.P.; Nibbering, E.T.J.; Pines, E.; Elsaesser, T. Large-amplitude Transfer Motion of Hydrated Excess Protons Mapped by Ultrafast 2D IR Spectroscopy. Science 2017, 357, 491-495. [CrossRef] [PubMed]

14. Kundu, A.; Dahms, F.; Fingerhut, B.P.; Nibbering, E.T.J.; Pines, E.; Elsaesser, T. Ultrafast Vibrational Relaxation and Energy Dissipation of Hydrated Excess Protons in Polar Solvents. Chem. Phys. Lett. 2018, 713, 111-116. [CrossRef]

15. Dahms, F.; Costard, R.; Pines, E.; Fingerhut, B.P.; Nibbering, E.T.J.; Elsaesser, T. The Hydrated Excess Proton in the Zundel Cation $\mathrm{H}_{5} \mathrm{O}_{2}{ }^{+}$: The Role of Ultrafast Solvent Fluctuations. Angew. Chem. Int. Ed. 2016, 55, 10600-10605. [CrossRef]

16. Kiefer, P.M.; Pines, E.; Pines, D.; Hynes, J.T. Solvent-Induced Red-Shifts for the Proton Stretch Vibrational Frequency in a Hydrogen-Bonded Complex. 1. A Valence Bond-Based Theoretical Approach. J. Phys. Chem. B 2014, 118, 8330-8351. [CrossRef]

17. Keinan, S.; Pines, D.; Kiefer, P.M.; Hynes, J.T.; Pines, E. Solvent-Induced O-H Vibration Red-Shifts of

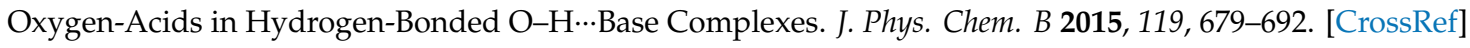

18. Ditkovich, J.; Mukra, T.; Pines, D.; Huppert, D.; Pines, E. Bifunctional Photoacids: Remote Protonation Affecting Chemical Reactivity. J. Phys. Chem. B 2015, 119, 2690-2701. [CrossRef]

19. Scherrer, A.; Agostini, F.; Sebastiani, D.; Gross, E.K.U.; Vuilleumier, R. On the Mass of Atoms in Molecules: Beyond the Born-Oppenheimer Approximation. Phys. Rev. X 2017, 7, 031035. [CrossRef]

20. Perrin, C.L. Symmetry of Hydrogen Bonds in Solution. Pure Appl. Chem. 2009, 81, 571-583. [CrossRef]

21. Perrin, C.L.; Karri, P.; Moore, C.; Rheingold, A.L. Hydrogen-Bond Symmetry in Difluoromaleate Monoanion. J. Am. Chem. Soc. 2012, 134, 7766-7772. [CrossRef]

22. Dopieralski, P.; Perrin, C.L.; Latajka, Z. On the Intramolecular Hydrogen Bond in Solution: Car-Parrinello and Path Integral Molecular Dynamics Perspective. J. Chem. Theory Comput. 2011, 7, 3505-3513. [CrossRef] [PubMed]

23. Shenderovich, I.G.; Burtsev, A.P.; Denisov, G.S.; Golubev, N.S.; Limbach, H.-H. Influence of the temperature-dependent dielectric constant on the H/D isotope effects on the NMR chemical shifts and the hydrogen bond geometry of the collidine-HF complex in $\mathrm{CDF}_{3} / \mathrm{CDClF}_{2}$ solution. Magn. Reson. Chem. 2001, 39, S91-S99. [CrossRef]

24. Shenderovich, I.G.; Tolstoy, P.M.; Golubev, N.S.; Smirnov, S.N.; Denisov, G.S.; Limbach, H.-H. Low-Temperature NMR Studies of the Structure and Dynamics of a Novel Series of Acid-;Base Complexes of HF with Collidine Exhibiting Scalar Couplings Across Hydrogen Bonds. J. Am. Chem. Soc. 2003, 125, 11710-11720. [CrossRef] [PubMed]

25. Lesnichin, S.B.; Tolstoy, P.M.; Limbach, H.-H.; Shenderovich, I.G. Counteranion-Dependent Mechanisms of Intramolecular Proton Transfer in Aprotic Solution. Phys. Chem. Chem. Phys. 2010, 12, 10373-10379. [CrossRef] [PubMed]

26. Pollice, R.; Fleckenstein, F.; Shenderovich, I.; Chen, P. Compensation of London Dispersion in the Gas Phase and in Aprotic Solvents. Angew. Chem. Int. Ed. 2019, 58, 14281-14288. [CrossRef]

27. Pollice, R.; Bot, M.; Kobylianskii, I.J.; Shenderovich, I.; Chen, P. Attenuation of London Dispersion in Dichloromethane Solutions. J. Am. Chem. Soc. 2017, 139, 13126-13140. [CrossRef]

28. Vyalikh, A.; Emmler, T.; Shenderovich, I.; Zeng, Y.; Findenegg, G.H.; Buntkowsky, G. H-2-solid state NMR and DSC study of isobutyric acid in mesoporous silica materials. Phys. Chem. Chem. Phys. 2007, 9, 2249-2257. [CrossRef]

29. Grabowski, S.J. Analysis of Hydrogen Bonds in Crystals. Crystals 2016, 6, 59. [CrossRef]

30. Grabowski, S.J. [FHF] $]^{-}$-The Strongest Hydrogen Bond under the Influence of External Interactions. Crystals 2016, 6, 3. [CrossRef] 
31. Vener, M.V.; Chernyshov, I.Y.; Rykounov, A.A.; Filarowski, A. Structural and spectroscopic features of proton hydrates in the crystalline state. Solid-state DFT study on $\mathrm{HCl}$ and triflic acid hydrates. Mol. Phys. 2018, 116, 251-262. [CrossRef]

32. Mukhopadhyay, M.; Banerjee, D.; Koll, A.; Mandal, A.; Filarowski, A.; Fitzmaurice, D.; Das, R.; Mukherjee, S. Excited state intermolecular proton transfer and caging of salicylidine-3,4,7-methyl amine in cyclodextrins. J. Photochem. Photobiol. A Chem. 2005, 175, 94-99. [CrossRef]

33. Pylaeva, S.A.; Elgabarty, H.; Sebastiani, D.; Tolstoy, P.M. Symmetry and Dynamics of FHF ${ }^{-}$Anion in Vacuum, in $\mathrm{CD}_{2} \mathrm{Cl}_{2}$ and in $\mathrm{CCl}_{4}$. Ab Initio MD Study of Fluctuating Solvent-Solute Hydrogen and Halogen Bonds. Phys. Chem. Chem. Phys. 2017, 19, 26107-26120. [CrossRef] [PubMed]

34. Koeppe, B.; Pylaeva, S.A.; Allolio, C.; Sebastiani, D.; Nibbering, E.T.J.; Denisov, G.S.; Limbach, H.-H.; Tolstoy, P.M. Polar solvent fluctuations drive proton transfer in hydrogen bonded complexes of carboxylic acid with pyridines: NMR, IR and ab initio MD study. Phys. Chem. Chem. Phys. 2017, 19, 1010-1028. [CrossRef] [PubMed]

35. Tomasi, J.; Mennucci, B.; Cammi, R. Quantum mechanical continuum solvation models. Chem. Rev. 2005, 105, 2999-3093. [CrossRef]

36. Shenderovich, I.G. Simplified calculation approaches designed to reproduce the geometry of hydrogen bonds in molecular complexes in aprotic solvents. J. Chem. Phys. 2018, 148, 124313. [CrossRef]

37. Marenich, A.V.; Cramer, C.J.; Truhlar, D.G. Universal Solvation Model Based on Solute Electron Density and on a Continuum Model of the Solvent Defined by the Bulk Dielectric Constant and Atomic Surface Tensions. J. Phys. Chem. B 2009, 113, 6378-6396. [CrossRef]

38. Mori, Y.; Takano, K. Location of protons in $\mathrm{N}-\mathrm{H} \cdots \mathrm{N}$ hydrogen-bonded systems: A theoretical study on intramolecular pyridine-dihydropyridine and pyridine-pyridinium pairs. Phys. Chem. Chem. Phys. 2012, 14, 11090-11098. [CrossRef]

39. Hofmeister, C.; Coto, P.B.; Thoss, M. Controlling the Conductance of Molecular Junctions Using Proton Transfer Reactions: A Theoretical Model Study. J. Chem. Phys. 2017, 146, 092317. [CrossRef]

40. Liang, H.; Chai, B.; Chen, G.; Chen, W.; Chen, S.; Xiao, H.; Lin, S. Electric Field-driven Acid-base Transformation: Proton Transfer from Acid $(\mathrm{HBr} / \mathrm{HF})$ to Base $\left(\mathrm{NH}_{3} / \mathrm{H}_{2} \mathrm{O}\right)$. Chem. Res. Chin. Univ. 2015, 31, 418-426. [CrossRef]

41. Dominikowska, J.; Palusiak, M. Tuning Aromaticity of para-Substituted Benzene Derivatives with an External Electric Field. ChemPhysChem 2018, 19, 590-595. [CrossRef]

42. Shenderovich, I.G.; Denisov, G.S. Solvent effects on acid-base complexes. What is more important: A macroscopic reaction field or solute-solvent interactions? J. Chem. Phys. 2019, 150, 204505. [CrossRef] [PubMed]

43. Chan, B.; Del Bene, J.E.; Radom, L. What Factors Determine Whether a Proton-Bound Homodimer Has a Symmetric or an Asymmetric Hydrogen Bond? Mol. Phys. 2009, 107, 1095-1105. [CrossRef]

44. Kong, S.; Borissova, A.O.; Lesnichin, S.B.; Hartl, M.; Daemen, L.L.; Eckert, J.; Antipin, M.Y.; Shenderovich, I.G. Geometry and Spectral Properties of the Protonated Homodimer of Pyridine in the Liquid and Solid States. A Combined NMR, X-ray Diffraction and Inelastic Neutron Scattering Study. J. Phys. Chem. A 2011, 115, 8041-8048. [CrossRef] [PubMed]

45. Melikova, S.M.; Rutkowski, K.S.; Gurinov, A.A.; Denisov, G.S.; Rospenk, M.; Shenderovich, I.G. FTIR Study of the Hydrogen Bond Symmetry in Protonated Homodimers of Pyridine and Collidine in Solution. J. Mol. Struct. 2012, 1018, 39-44. [CrossRef]

46. Tolstoy, P.M.; Smirnov, S.N.; Shenderovich, I.G.; Golubev, N.S.; Denisov, G.S.; Limbach, H.-H. NMR studies of solid state-Solvent and H/D isotope effects on hydrogen bond geometries of 1:1 complexes of collidine with carboxylic acids. J. Mol. Struct. 2004, 700, 19-27. [CrossRef]

47. Andreeva, D.V.; Ip, I.; Gurinov, A.A.; Tolstoy, P.M.; Denisov, G.S.; Shenderovich, I.G.; Limbach, H.-H. Geometrical Features of Hydrogen Bonded Complexes Involving Sterically Hindered Pyridines. J. Phys. Chem. A 2006, 110, 10872-10879. [CrossRef]

48. Lankau, T.; Yu, C.-H. A quantum description of the proton movement in an idealized $\mathrm{NHN}^{+}$bridge. Phys. Chem. Chem. Phys. 2011, 13, 12758-12769. [CrossRef]

49. Asmis, K.R.; Yang, Y.; Santambrogio, G.; Brümmer, M.; Roscioli, J.R.; McCunn, L.R.; Johnson, M.A.; Kühn, O. Gas-Phase Infrared Spectroscopy and Multidimensional Quantum Calculations of the Protonated Ammonia Dimer $\mathrm{N}_{2} \mathrm{H}_{7}{ }^{+}$. Angew. Chem. Int. Ed. 2007, 46, 8691-8694. [CrossRef] 
50. Giese, K.; Petković, M.; Naundorf, H.; Kühn, O. Multidimensional quantum dynamics and infrared spectroscopy of hydrogen bonds. Phys. Rep. 2006, 430, 211-276. [CrossRef]

51. Limbach, H.-H.; Tolstoy, P.M.; Pérez-Hernández, N.; Guo, J.; Shenderovich, I.G.; Denisov, G.S. OHO Hydrogen Bond Geometries and NMR Chemical Shifts: From Equilibrium Structures to Geometric H/D Isotope Effects, with Applications for Water, Protonated Water, and Compressed Ice. Israel J. Chem. 2009, 49, 199-216. [CrossRef]

52. Sharif, S.; Shenderovich, I.G.; González, L.; Denisov, G.S.; Silverman, D.H.; Limbach, H.-H. Nuclear Magnetic Resonance and ab Initio Studies of Small Complexes Formed between Water and Pyridine Derivatives in Solid and Liquid Phases. J. Phys. Chem. A 2007, 111, 6084-6093. [CrossRef] [PubMed]

53. Shenderovich, I.G. The Partner Does Matter: The Structure of Heteroaggregates of Acridine Orange in Water. Molecules 2019, 24, 2816. [CrossRef] [PubMed]

54. Gurinov, A.A.; Mauder, D.; Akcakayiran, D.; Findenegg, G.H.; Shenderovich, I.G. Does Water Affect the Acidity of Surfaces? The Proton-Donating Ability of Silanol and Carboxylic Acid Groups at Mesoporous Silica. Chem. Phys. Chem. 2012, 13, 2282-2285. [CrossRef] [PubMed]

55. Kunz, W. Specific ion effects in colloidal and biological systems. Curr. Opin. Colloid Interface Sci. 2010, 15, 34-39. [CrossRef]

56. Sham, Y.Y.; Chu, Z.T.; Warshel, A. Consistent Calculations of pKa's of Ionizable Residues in Proteins: Semi-microscopic and Microscopic Approaches. J. Phys. Chem. B 1997, 101, 4458-4472. [CrossRef]

57. Rossini, E.; Bochevarov, A.D.; Knapp, E.W. Empirical Conversion of pKa Values between Different Solvents and Interpretation of the Parameters: Application to Water, Acetonitrile, Dimethyl Sulfoxide, and Methanol. ACS Omega 2018, 3, 1653-1662. [CrossRef]

58. Gurinov, A.A.; Denisov, G.S.; Borissova, A.O.; Goloveshkin, A.S.; Greindl, J.; Limbach, H.-H.; Shenderovich, I.G. NMR Study of Solvation Effect on the Geometry of Proton-Bound Homodimers of Increasing Size. J. Phys. Chem. A 2017, 121, 8697-8705. [CrossRef]

59. Gurinov, A.A.; Lesnichin, S.B.; Limbach, H.-H.; Shenderovich, I.G. How Short is the Strongest Hydrogen Bond in the Proton-Bound Homodimers of Pyridine Derivatives? J. Phys. Chem. A 2014, 118, 10804-10812. [CrossRef]

60. Hunter, E.P.L.; Lias, S.G. Evaluated Gas Phase Basicities and Proton Affinities of Molecules: An Update. J. Phys. Chem. Ref. Data 1998, 27, 413-656. [CrossRef]

61. Bräuer, P.; Situmorang, O.; Ng, P.L.; D'Agostino, C. Effect of Al content on the strength of terminal silanol species in ZSM-5 zeolite catalysts: A quantitative DRIFTS study without the use of molar extinction coefficients. Phys. Chem. Chem. Phys. 2018, 20, 4250-4262. [CrossRef]

62. Błaziak, K.; Sendys, P.; Danikiewicz, W. Experimental versus Calculated Proton Affinities for Aromatic Carboxylic Acid Anions and Related Phenide Ions. ChemPhysChem 2016, 17, 850-858. [CrossRef] [PubMed]

63. Bieńkowski, P.; Świder, P.; Błaziak, K.; Danikiewicz, W. Proton affinities of the anions of aromatic carboxylic acids measured by kinetic method. Int. J. Mass Spectrom. 2014, 357, 29-33. [CrossRef]

64. Ervin, K.M. Experimental Techniques in Gas-Phase Ion Thermochemistry. Chem. Rev. 2001, 101, $391-444$. [CrossRef] [PubMed]

65. Pylaeva, S.; Allolio, C.; Koeppe, B.; Denisov, G.S.; Limbach, H.-H.; Sebastiani, D.; Tolstoy, P.M. Proton transfer in a short hydrogen bond caused by solvation shell fluctuations: An ab initio MD and NMR/UV study of an (OHO) $)^{-}$bonded system. Phys. Chem. Chem. Phys. 2015, 17, 4634-4644. [CrossRef]

66. Golubev, N.S.; Shenderovich, I.G.; Smirnov, S.N.; Denisov, G.S.; Limbach, H.-H. Nuclear Scalar Spin-Spin Coupling Reveals Novel Properties of Low-Barrier Hydrogen Bonds in a Polar Environment. Chem. Eur. J. 1999, 5, 492-497. [CrossRef]

67. Del Bene, J.E.; Bartlett, R.J.; Elguero, J. Interpreting ${ }^{2 \mathrm{~h}} \mathrm{~J}(\mathrm{~F}, \mathrm{~N}),{ }^{1 \mathrm{~h}} \mathrm{~J}(\mathrm{H}, \mathrm{N})$ and ${ }^{1} \mathrm{~J}(\mathrm{~F}, \mathrm{H})$ in the hydrogen-bonded FH-collidine complex. Magn. Reson. Chem. 2002, 40, 767-771. [CrossRef]

68. Frisch, M.J.; Trucks, G.W.; Schlegel, H.B.; Scuseria, G.E.; Robb, M.A.; Cheeseman, J.R.; Scalmani, G.; Barone, V.; Mennucci, B.; Petersson, G.A.; et al. Gaussian 09, Revision D.01; Gaussian, Inc.: Wallingford, CT, USA, 2013.

69. Chai, J.-D.; Head-Gordon, M. Long-range corrected hybrid density functionals with damped atom-atom dispersion corrections. Phys. Chem. Chem. Phys. 2008, 10, 6615-6620. [CrossRef]

70. Weigend, F.; Ahlrichs, R. Balanced basis sets of split valence, triple zeta valence and quadruple zeta valence quality for H to Rn: Design and assessment of accuracy. Phys. Chem. Chem. Phys. 2005, 7, 3297-3305. [CrossRef] 
71. Winget, P.; Dolney, D.M.; Giesen, D.J.; Cramer, C.J.; Truhlar, D.G. Minnesota Solvent Descriptor Database. Available online: http://comp.chem.umn.edu/solvation/mnsddb.pdf (accessed on 20 January 2020).

72. Zhu, H.; Blom, M.; Compagnon, I.; Rijs, A.M.; Roy, S.; von Helden, G.; Schmidt, B. Conformations and Vibrational Spectra of a Model Tripeptide: Change of Secondary Structure upon Micro-Solvation. Phys. Chem. Chem. Phys. 2010, 12, 3415-3425. [CrossRef]

73. Moser, A.; Range, K.; York, D.M. Accurate Proton Affinity and Gas-Phase Basicity Values for Molecules Important in Biocatalysis. J. Phys. Chem. B 2010, 114, 13911-13921. [CrossRef]

74. Manriquez, R.; Lopez-Dellamary, F.A.; Frydel, J.; Emmler, T.; Breitzke, H.; Buntkowsky, G.; Limbach, H.-H.; Shenderovich, I.G. Solid-State NMR Studies of Aminocarboxylic Salt Bridges in L-Lysine Modified Cellulose. J. Phys. Chem. B 2009, 113, 934-940. [CrossRef] [PubMed]

75. Mauder, D.; Akcakayiran, D.; Lesnichin, S.B.; Findenegg, G.H.; Shenderovich, I.G. Acidity of Sulfonic and Phosphonic AcidFunctionalized SBA-15 under Almost WaterFree Conditions. J. Phys. Chem. C 2009, 113, 19185-19192. [CrossRef]

76. Ip, B.C.K.; Shenderovich, I.G.; Tolstoy, P.M.; Frydel, J.; Denisov, G.S.; Buntkowsky, G.; Limbach, H.-H. NMR Studies of Solid Pentachlorophenol-4-Methylpyridine Complexes Exhibiting Strong OHN Hydrogen Bonds: Geometric H/D Isotope Effects and Hydrogen Bond Coupling Cause Isotopic Polymorphism. J. Phys. Chem. A 2012, 116, 11370-11387. [CrossRef] [PubMed]

77. Levina, V.A.; Filippov, O.A.; Gutsul, E.I.; Belkova, N.V.; Epstein, L.M.; Lledós, A.; Shubina, E.S. Neutral Transition Metal Hydrides as Acids in Hydrogen Bonding and Proton Transfer: Media Polarity and Specific Solvation Effects. J. Am. Chem. Soc. 2010, 132, 11234-11246. [CrossRef]

78. Dub, P.A.; Baya, M.; Houghton, J.; Belkova, N.V.; Daran, J.-C.; Poli, R.; Epstein, L.M.; Shubina, E.S. Solvent Control in the Protonation of $\left[\mathrm{Cp}^{*} \mathrm{Mo}(\mathrm{dppe}) \mathrm{H}_{3}\right]$ by $\mathrm{CF}_{3} \mathrm{COOH}$. Eur. J. Inorg. Chem. 2007, 2007, 2813-2826. [CrossRef]

79. Belkova, N.V.; Gribanova, T.N.; Gutsul, E.I.; Minyaev, R.M.; Bianchini, C.; Peruzzini, M.; Zanobini, F.; Shubina, E.S.; Epstein, L.M. Specific and non-specific influence of the environment on dihydrogen bonding

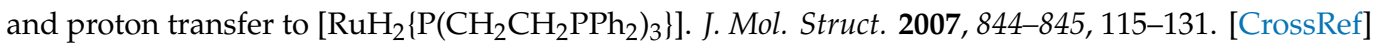

80. Belkova, N.V.; Besora, M.; Epstein, L.M.; Lledós, A.; Maseras, F.; Shubina, E.S. Influence of Media and Homoconjugate Pairing on Transition Metal Hydride Protonation. An IR and DFT Study on Proton Transfer to CpRuH(CO)(PCy3). J. Am. Chem. Soc. 2003, 125, 7715-7725. [CrossRef]

81. Shenderovich, I.G.; Smirnov, S.N.; Denisov, G.S.; Gindin, V.A.; Golubev, N.S.; Dunger, A.; Reibke, R.; Kirpekar, S.; Malkina, O.L.; Limbach, H.-H. Nuclear Magnetic Resonance of Hydrogen Bonded Clusters between $\mathrm{F}^{-}$and $(\mathrm{HF})_{\mathrm{n}}$ : Experiment and Theory. Ber. Bunsenges. 1998, 102, 422-428. [CrossRef]

82. Golubev, N.S.; Melikova, S.M.; Shchepkin, D.N.; Shenderovich, I.G.; Tolstoy, P.M.; Denisov, G.S. nterpretation of hydrogen/deuterium isotope effects on NMR chemical shifts of [FHF] $]^{-}$ion based on calculations of nuclear magnetic shielding tensor surface. Z. Phys. Chem. 2003, 217, 1549-1563. [CrossRef]

83. Vener, M.V.; Kong, S.; Levina, A.A.; Shenderovich, I.G. Spectroscopic Signatures of $\left[\mathrm{H}_{9} \mathrm{O}_{4}\right]^{+}$and $\left[\mathrm{H}_{13} \mathrm{O}_{6}\right]^{+}$ Ions in a Polar Aprotic Environment Revealed under DFT-PCM Approximation. Acta Chim. Slov. 2011, 58, 402-410.

Sample Availability: Not available.

(C) 2020 by the authors. Licensee MDPI, Basel, Switzerland. This article is an open access article distributed under the terms and conditions of the Creative Commons Attribution (CC BY) license (http://creativecommons.org/licenses/by/4.0/). 